\title{
Narrativas infantis como possibilidade de simbolizar os conflitos da infância: uma análise com base no conto $O$ Patinho Feio
}

\author{
Andressa de Souza Ferreira" \\ Maristela Piva* \\ Patrícia da Silva Valério****
}

\section{Resumo}

O objetivo deste estudo é identificar e descrever a importância da contação de histórias para o desenvolvimento psíquico emocional das crianças. Assim, busca, a partir do resgate da versão original do conto $O$ Patinho Feio, de Andersen, refletir sobre a possibilidade de as narrativas se tornarem importantes instrumentos para trazer à tona conflitos emergentes, especialmente na infância, vindo a contribuir para a identificação e a elaboração, de forma lúdica, de conteúdos que podem causar angústia ao indivíduo, permitindo-lhes a reorganização de seu estado psíquico emocional.

Palavras-chave: Narrativas infantis. Infância. Simbolização.

* Psicóloga, Universidade de Passo Fundo, RS. E-mail: dsfandressa@gmail.com

** Possui graduação em Psicologia pela Universidade de Passo Fundo (1986). Especialização em Diagnóstico Psicológico pela PUCRS, e Mestrado em Psicologia pela Pontifícia Universidade Católica do Rio Grande do Sul (1999). Doutoranda em História (PPGEDU UPF). Docente Titular II da Universidade de Passo Fundo, no Curso de Psicologia, atualmente exerce a função de Assessora da Vice Reitoria de Graduação. Tem experiência na área de Psicologia, com ênfase em Intervenção Terapêutica, atuando principalmente nos seguintes temas: relações familiares, divórcio e mediação familiar. Violência doméstica, Psicoterapia, Infertilidade e aspectos psicológicos. E-mail: maristela@upf.br

**** Doutora em Linguística Aplicada pela Unisinos, mestre em Letras pela Universidade de Passo Fundo e graduada em Letras pela Universidade de Passo Fundo. É professora do Curso de Letras e do Programa de Pós-graduação em Letras da UPF e desenvolve estudos na linha de "Constituição e interpretação do texto e do discurso”. E-mail: patriciav@upf.br

Data de submissão: set. 2017 - Data de aceite: out. 2017

http://dx.doi.org/10.5335/rdes.v13i3.7402 


\section{Introdução}

As narrativas infantis, sejam as que tratam de acontecimentos sociais cotidianos ou as voltadas ao mundo feérico, de príncipes e fadas, existem há anos e estão presentes nos quatro cantos do mundo. De acordo com Coelho (1987), tiveram início como contos direcionados para adultos e, somente mais tarde, foram reescritas e adaptadas ao público infantil. Percebemos a sua existência no ambiente familiar, no meio escolar, tendo sido transmitidas ao longo das gerações. Com isso, tornaram-se histórias transgeracionais. Conforme Santos, Santos Filho e Aquino (2009), desde o começo da infância, senão ainda no útero da mãe, a contação de histórias é um instrumento muito utilizado e bem aceito por crianças e adultos. Seja pelo poder de entreter as crianças ou de possibilitar a compreensão de conflitos emergentes.

No Brasil e em Portugal, os contos de fadas, como são conhecidos hoje, surgiram no final do século XIX, levando o nome de contos da carochinha (SCHNEIDER; TOROSSIAN, 2009). Existem comprovações bastante antigas sobre os contos e seu uso nas mais diversas culturas. Os contos de fadas, em especial, têm maravilhado várias gerações em diferentes países e antes mesmo de se tornarem registrados de forma escrita como os conhecemos, eram responsáveis pela formação dos indivíduos, de sua espiritualidade e também da cultura de inúmeros povos (OLIVEIRA, 1993 apud SCHNEIDER; TOROSSIAN, 2009).
Bettelheim (1903), ao tentar entender a razão de as histórias terem tanto êxito no enriquecimento da vida interior infantil, percebeu que os contos, num sentido bem mais profundo do que outros tipos de leitura, começam onde a criança se encontra em seu real estado psicológico emocional. Esses falam de pressões internas graves de maneira que a criança, inconscientemente, compreende. Oferecem exemplos tanto de soluções temporárias, quanto permanentes para dificuldades urgentes.

Desse modo, o objetivo deste estudo, caracterizado como uma pesquisa qualitativa e descritiva com caráter explicativo, foi compreender a importância da contação de histórias para o desenvolvimento psíquico emocional das crianças, bem como refletir sobre a possibilidade de as narrativas se tornarem importantes instrumentos para trazer à tona conflitos emergentes, especialmente na infância, vindo a contribuir para a identificação e a elaboração, de forma lúdica, de conteúdos que podem causar angústia ao indivíduo, permitindo-lhes a reorganização de seu estado psíquico emocional. Assim, escolhemos o conto infantil $O$ Patinho Feio, ${ }^{1}$ para explicitar essa possibilidade, acreditando que, seja através dos contos, ou por meio dos mitos e lendas, constituímos espaços nos quais, ao longo dos tempos, conseguimos encurtar a solidão, balizando a criação particular do mundo e de nós mesmos (CORSO; CORSO, 2011). 


\section{Narrativas como possibilidade de construção humana}

Corso e Corso (2011) compreenderam que a humanidade pensou por intermédio dos mitos, durante a maior parte de sua vida. Sendo um resumo de histórias, os mitos eram uma maneira de pensar, organizavam uma visão de mundo e, através dessa visão, respondiam-se a indagações de quem os escutava. O mito tinha uma poderosa força intelectual que, ao modo dos sonhos ou do que não tinha razão, tentava assimilar o todo na formação de um sentido. As pessoas encontravam, nos mitos, seus limites e possibilidades. Todo o saber cabia dentro do mito e os novos fatos que iam acontecendo seriam contados por meio dele também.

Já os contos de fadas, segundo Santos, Santos Filho e Aquino (2009), surgiram emergentes e de forma oral. Consideradas boas histórias, eram destinadas ao público adulto e, mais tarde, foram adaptadas, e seu uso contribuiu para a preparação de uma elite cultural. Ao longo de muitos séculos, foi o tipo de produção favorita das classes populares.

As contações de histórias vêm para todos nós como um dos primeiros incentivos intelectuais. Para Coelho (1987), a partir dos contos infantis ouvidos na infância, podemos construir percepções das primeiras figuras heroicas e, possivelmente, desenvolver sentimentos bons ou ruins. De acordo com Coelho (1987), as narrativas se dividiram em dois grupos importantes: os Contos de Fadas e Contos Maravilhosos. Sendo assim, a efabulação básica do conto de fadas expressa os obstáculos que precisam ser vencidos, como ritual iniciático verdadeiro, para que o herói consiga alcançar sua autorrealização, seja encontrando o seu verdadeiro eu, seja encontrando a princesa, que encarna o ideal a ser alcançado. Já os Contos Maravilhosos originaram-se das narrativas orientais e enfatizam a parte material/sensorial/ética do ser humano: suas necessidades básicas.

As histórias infantis, sejam elas classificadas como maravilhosas ou contos de fadas, não comprovam a garantia de alegria, nem de uma vida de sucesso para o indivíduo que a escuta, mas podem servir em determinados momentos da vida como ajuda. Portanto, uma criança, quando escuta uma história, poderia desenvolver a capacidade de simbolizar tal conflito dentro dela, por meio de histórias específicas para o momento em que ela se encontra (CORSO; CORSO, 2006).

No conto infantil $O$ Patinho Feio, observamos que a matéria narrativa é construída por um narrador onisciente que conta, de forma amiga e familiar, uma história que ele conhece bem: a de um patinho que nasceu feio, grande e desajeitado e, em consequência, era maltratado por todos. O tempo passou, ele cresceu e descobriu-se, de repente, transformado em um lindo cisne (COELHO, 1997). Por meio desse conto, crianças e humanos se identificam com o patinho. Se alguém duvida da possibilidade de 
a criança se identificar com animais, é porque ainda não as viu construir ternos diálogos com seus animais de estimação. Quando se observa esses momentos, vê-se que os animais se adaptam a seus amos e demonstram, num movimento de orelhas, num ronronar, que entendem e assimilam as mensagens e ordens que lhes são dadas. Assim, as fábulas estão repletas de ensinamentos valiosos, por meio dos quais os animais indicam como devemos fazer e nos comportar nas variadas circunstâncias (DORFMAN; MATTELART, 1982).

Também a psicologia compreendeu a facilidade de a criança se identificar com animais. Nesse ponto, podemos observar que alguns testes psicológicos se utilizaram de figuras de animais para facilitar a expressão do mundo interno das crianças. É o caso do Teste de Percepção Infantil, conhecido como CAT, criado por Bellak e Hurvich (1992, p. 5) que, ao definir a técnica esclarece que "as figuras de animais têm a vantagem de serem mais livres do ponto de vista cultural e menos estruturadas em relação à sexualidade e à idade do que as figuras humanas". Entre os estudos revisados, os de Budoff e especialmente os de Weisskopf-Joelson e Foster sugeriram que algumas crianças parecem se dar melhor com os estímulos animais e outras com estímulos humanos. Essas preferências podem estar associadas com as variáveis específicas de cada personalidade. Por exemplo, aqueles que têm dificuldades na produção de respostas parecem ter mais facilidades com as figuras animais (BELLAK; HURVICH, 1992).

Para além da possibilidade de humanos se identificarem com animais, Rosa (2015) pontua a essência que nos constitui como seres humanos: a possibilidade de construir narrativas que se resumem em palavra e memória. O objetivo da palavra é que o indivíduo faça uso dela para um ganho de sentido sobre si mesmo, para vasculhar e descrever os seus afetos, registrar, dar lugar e qualidade ao pensamento. É uma ação de vida que é indispensável para existência psíquica e para o indivíduo lidar com a sua vida. A palavra é a artilharia que temos para enfrentar a incessável tarefa de nos constituirmos seres humanos. Ou, para empregar as palavras de Benveniste (1995, p. 286), "é na linguagem e pela linguagem que o homem se constitui como sujeito". As narrativas, portanto, são artefatos simbólicos de alta potência para juntar cuidadosamente os fios da existência, a condição humana, o convívio afetivo hoje tão raro de se encontrar. Por esse motivo, o contato com a literatura, desde a infância, não é desnecessário ou dispensável. Mas, sim, fundamental.

\section{Contos como possibilidades terapêuticas}

A experiência contemporânea com contos infantis é narrada por Gutfreind (2003, apud SCHNEIDER; TOROSSIAN, 2009) quando fala que os contos já desempenhariam funções terapêutica 
desde a sua origem, sendo este fato que explicaria a sua permanência e transmissão transgeracional, ao longo dos séculos. $\mathrm{O}$ conto favorece uma reflexão íntima e interior, pois é através dele que a criança tem a possibilidade de refletir sobre seus sentimentos, tendo a esperança de que o seu sofrimento seja passageiro.

Quando se trata de crianças fragilizadas ou até mesmo doentes, percebe-se que essas apreciam textos que relatem seus problemas. As problemáticas, sendo tratadas como universais, garantem a ela não estar sozinha em sua dor. Assim, tanto $o$ ato de ler ou de contar histórias produz reflexões. Mesmo diante da solidão, de dia ou à noite, ao relembrar da história, é possível que a criança se sinta reconfortada, pois os contos são fontes de prazer para elas, tanto pelo ato de ouvir ou pela representação que causa (CALDIN, 2004 apud SCHNEIDER; TOROSSIAN, 2009).

Não sendo importante somente para crianças, os contos de fadas são um dispositivo de intervenção na clínica psicológica, que podem ser muito bem utilizados para adultos. Segundo Hisada (1998, apud SCHNEIDER; TOROSSIAN, 2009), os pacientes se utilizam de histórias como um instrumento para comunicar algo. Os contos ou histórias agem como um recurso para diminuir a angústia, o que propicia ao paciente se aproximar de suas dificuldades, pois, por intermédio das histórias, é possível reviver alguns aspectos mais primitivos, em um contexto lúdico. Com isso, o indivíduo não precisará abrigar-se em uma organização defensiva patológica, ou desenvolver um sintoma pelo qual o corpo permaneça sofrendo no lugar da sua mente.

Mesmo a contação de histórias a um grupo de crianças pode produzir efeitos positivos, já que, conforme Machado (2004), cada criança apreende a história à sua maneira. A criança necessita que lhe sejam dadas sugestões sobre a forma como ela pode lidar com essas questões e crescer para a maturidade. Isso pode ser feito, de maneira simbólica, ouvindo narrativas.

O poeta alemão Schiller escreveu: "Há maior significado profundo nos contos de fadas que me contaram na infância do que na verdade que a vida ensina" (THE PICCOLOMINI, III, 4 apud BETTELHEIM, 1903).

Corso e Corso (2011, p. 20), por sua vez, afirmam que "muitos analistas, psicólogos e pedagogos reconhecem que existe um aspecto lúdico significativo envolvido nas histórias. Mas, elas são muito mais do que isso. As crianças usam as histórias como sistemas para organizar sua vida e seus impasses".

Dessa forma, o caminho da literatura, em especial da literatura infantil, como foi retratado nos parágrafos anteriores, pode ser um excelente recurso para diminuir a angústia, e também servir como possibilidade simbólica para determinados momentos de uma vida.

Na sequência, apresentamos um breve resumo do conto original $O$ Patinho Feio $^{2}$ para, em seguida, discutir elemen- 
tos que consideramos potenciais para descrever algumas possibilidades de ressignificação dos conflitos na infância.

O conto $O$ Patinho Feio retrata a história de um filhote de cisne, chocado no ninho de uma pata. $O$ filhote de cisne demorava a romper a casca, enquanto os ovos de todos os patinhos da ninhada já haviam descascado. Assim, um dia, uma velha pata vem lhe fazer uma visita e pede para ver o ovo que não quebra. Ao observar o ovo, a velha pata diz que, pelo tamanho, esse ovo só pode ser de peru e aconselha a mãe a largá-lo e cuidar dos filhotes nascidos, ensinando-os a nadar. A mãe pata diz que vai chocar o ovo mais um pouco, pois, para quem ficara até aquele dia, o que seria aguentar mais uns dias? Assim, mesmo cansada, a mãe pata permanece chocando o ovo de cisne.

Quando finalmente a casca do ovo rompeu, a mãe pata observou que o filhote era taludo e feio, diferente de todos os outros. Assim, no dia seguinte, a mãe pata foi com os filhotes para o canal, atirou-se à água, e pôs-se a chamar os patinhos. Vendo que o filhote nadava bem, a mãe certificou-se de era mesmo seu filho e pensou olhando-o bem, achou-o até muito bonito.

Um dia, entraram no quintal dos patos. Lá havia grande barulho de uma briga entre duas famílias de patos. A mãe ensina aos filhotes como devem se comportar em grupo, a quem cumprimentar, como mexer o pescoço, entre outras orientações de como se comportar em grupo. Os patos desse lugar, ao ver o bando, criticam a quantidade de patos com quem terão de dividir o espaço e comentam o quanto grande e esquisito é o filhote que nascera por último. Contudo, a mãe o defende, dizendo que ele podia não ser bonito, mas tinha bom gênio e nadava tão bem quanto qualquer um dos outros, senão até melhor. Diz ainda que, com o seu crescimento, poderia se tornar mais bonito e até um pouco menor, que havia passado tempo demais dentro do ovo, e por isso não saíra com boa estampa. Além disso, era um pato macho, portanto a mãe acreditava que ele seria bem forte e iria adiante. Assim, enquanto todos os irmãos podiam transitar com tranquilidade pelo quintal, o pobre patinho feio era bicado, empurrado e escarnecido. Os patos o bicavam, as galinhas o beliscavam, e a moça encarregada de alimentá-los dava-lhe pontapés. Com o tempo, passou a ser maltratado até mesmo pelos irmãos. Até que um dia, aflito, o patinho fugiu correndo e voou por cima da cerca.

No percurso de sua fuga, encontrou marrecas, gansos selvagens, sendo por todos discriminado em razão de sua feiura. Chega um dia a um humilde casebre de um camponês pobre, onde não é recriminado em razão de seu aspecto físico. Mesmo assim, nem nesse lugar encontra sossego, pois como não põe ovos, nem sabe ronronar ou faiscar os olhos, não atende à expectativa dos moradores. Desse modo, o patinho feio parte novamente em busca de um lugar para nadar. Ao encontrar esse lugar, boiava e mergulhava, mas todos os animais o desprezavam pela feiura. Até que um certo dia, à hora do crepúsculo, saiu da mata todo um bando de grandes e garridas aves. $O$ patinho nunca vira antes aves tão lindas. Eram de um branco brilhante, com longo pescoço delgado e flexível. Eram cisnes. Mas como o inverno se aproximava, as aves acabaram partindo e voando alto para longe. Com a chegada do inverno, $o$ patinho era obrigado a nadar constantemente para evitar que a água congelasse de todo. Durante uma dessas noites frias, a fadiga o venceu e ele ficou imóvel, preso dentro do gelo. Na manhã seguinte, um camponês o encontrou, quebrou o gelo com o tamanco, libertando o patinho e levando-o para sua casa, dando-o de presente à sua mulher. $\mathrm{Na}$ casa, as crianças se aproximavam querendo brincar, mas o patinho, amedrontado, pensando que lhe queriam fazer mal, acaba fugindo mais uma vez.

Seria demasiado triste contar todas as misérias e privações pelas quais o patinho teve de passar durante o rigoroso inverno. Quando o sol voltou a aquecer a terra, o patinho abriu suas asas, que fizeram maior rumor que antes e o carregaram, potentes, para longe. Assim chegou a um pomar, onde tudo era delicioso e primaveril e pôde vislumbrar, 
saindo da mata, três formosos cisnes brancos, ruflando as penas, flutuando, leves e ligeiros sobre a água. Logo reconheceu-os e sentiu-se tomado de uma estranha melancolia. Nisso, decidiu ir ao encontro daquelas aves. Pensou que poderia ser morto, em razão de sua feiura, com as bicadas dessas aves. Mesmo assim, nadou em direção aos formosos cisnes, preferia ser morto pelas aves maravilhosas, do que continuar a ser maltratado e humilhado como até então.

Assim, curvando a cabeça para baixo, para água à espera da morte, viu sua própria imagem refletida na água cristalina. Mas não era a imagem de um pato, de um pardo e feio pato. Era um cisne que ele via no espelho da água. Dando-se conta de que era cisne e não pato, sentiu-se até satisfeito com as angústias e adversidades sofridas. Sentia agora a ventura, as maravilhas que o aguardavam. E os grandes cisnes nadaram ao redor dele, afagando-o com o bico. Crianças de aproximavam, atirando pão e farinha à água, e elogiavam sua beleza. Nunca sonhei tanta felicidade quando eu era um patinho feio, exultava intimamente o cisne.

\section{Um percurso de análise do conto $O$ Patinho Feio}

Observamos, a partir do enredo do conto $O$ Patinho Feio, a presença marcante de conflitos sociais, desencadeados pela ausência de características comuns a uma espécie. Há presença de sentimentos, como rejeição e maus-tratos. Corso e Corso (2006) explicam que as histórias infantis, mesmo sendo classificadas como maravilhosas ou contos de fada, não comprovam a garantia de alegria, nem de uma vida de sucesso para o indivíduo que a escuta, mas podem servir em determinados momentos da vida como ajuda.
Coelho (1987) menciona que o conto maravilhoso enfatiza a parte material, sensorial e ética do ser humano, assim como as suas necessidades básicas.

Percebemos que a história $O$ Patinho Feio é uma narrativa que não contém fadas, contudo, há a emergência de um mundo mágico, onde animais falam e o tempo e o espaço são reconhecíveis ou até mesmo familiares ao mundo cotidiano. A história traz uma problemática social, na qual o herói, no caso o patinho feio, busca a autorrealização. O que chama a atenção para esses contos maravilhosos é que, em geral, a miséria ou a necessidade de sobrevivência física são pontos de partida para as aventuras da busca. Pode-se constatar no conto que o patinho foi em busca de sobrevivência física, buscando reconhecimento de sua própria existência interna e externa.

Um dos primeiros aspectos a ser destacado no início do conto é quando a mãe pata recebe a visita de uma das patas do quintal, que lhe aconselha a abandonar o ovo, pois pelo seu tamanho poderia ser de peru. A mãe pata insiste em chocar o ovo, dizendo: "Vou ficar ainda mais um pouquinho em cima dele [...] Se já fiquei até agora, posso ficar mais uns dias" (p. 241). Tal ato revela uma mãe dedicada que, mesmo cansada, sabe respeitar o momento certo de cada filho, ainda que isso a leve a enfrentar mais alguns dias de sacrifício. Nesse caso, o conto pode servir como forma de elaboração simbólica dos conflitos existentes na vida, onde entendemos que cada filho 
necessita de um tempo específico para o seu desenvolvimento psíquico saudável e irá necessitar da compreensão e investimentos por parte de seu cuidador.

Quando o filhote saiu da casca, segundo a mãe pata "era taludo e feio" (p. 242). A mãe identifica que esse filhote é maior e diferente dos demais, revelando um sentimento de frustração já que a aparência do filhote não atende a suas expectativas imaginárias. Contudo, parece aceitar a diferença existente entre os filhos, reconhecendo o patinho feio como seu filho. Assume, assim, seu papel materno, investindo seu amor no patinho nascido por último, reforçando aspectos positivos no mesmo, como podemos ver ainda na p. 242: "Vejam como ele usa as pernas direitinho, como ergue a cabeça. É meu filho, sim! Olhando-se bem para ele, vê-se que é até muito bonito". Destacamos essa parte do conto, pois apresenta uma visão de mãe como alguém que aceita as diferenças, que torce pelo filho, que aceita, incondicionalmente, tudo que a criança pode trazer e ainda que esse frustre as suas expectativas, sinaliza sua apropriação como mãe daquele filhote. Compreendemos o quanto isso é importante e significativo para o processo de identificação da mãe com o seu bebê.

Outro aspecto que mostra uma mãe que estimula os filhotes ao crescimento, pode ser percebida, de forma simbólica, no trecho em que a mãe os leva ao quintal dos patos e diz:" Tratem de andar" (p. 242). A mãe vai transmitindo as re- gras e valores que existem na sociedade em que vivem:

[...] inclinem a cabeça para aquela pata velha, ali do outro lado. Ela é a mais nobre de todas nós. Tem sangue espanhol, e por isso é tão importante. Ela tem um pano vermelho na perna, estão vendo? É o que há de mais nobre. É a distinção máxima que se pode dar a qualquer pato: significa que não querem separa-se dela, e que ela tem de ser reconhecida pelos bichos e pela gente (p. 242-243).

Dessa forma, a mãe ensina aos filhos as origens de uma boa educação. Esses aspectos do conto traduzem o lugar da mãe como alguém que insere a cultura nos filhos, as regras, o comportamento esperado. Chama a atenção que o texto simboliza isso muito claramente, pois na continuidade do conto veremos que os animais do quintal comentavam: "olhem como é feio aquele patinho! Esse não vamos tolerar!" (p. 243), demonstrando a dificuldade de os pares em aceitar a diferença. Essa fala é muito semelhante ao que observamos na sociedade, quando temos uma rejeição ao diferente, quando, com frequência, aquilo que não corresponde à expectativa da normalidade é recusado por um determinado grupo. A exemplo disso, podemos citar a apologia à beleza no contemporâneo, quando uma criança ou adolescente se torna vítima de bullying, sendo considerada estranha ou não pertencente a determinado grupos da sociedade. O fenômeno bullying, conforme explicita Silva (2010), expõe não somente a intolerância às diferenças, como também dissemina os mais diversos preconceitos e a covardia nas relações interpessoais. 
No conto em questão, explicita-se a valorização da beleza como um grande atributo, de modo que a ausência dessa característica produz até mesmo violência física contra o patinho. A presença da referência positiva aos atributos de beleza em um conto de 1843 mostra que a estética da beleza, tão apregoada na sociedade atual, não é uma característica exclusiva desse nosso tempo. Conforme Teixeira (2001), o indivíduo está sempre em busca da recompensa pela beleza, principalmente corporal. Isso é comprovado na constante procura de parte das pessoas por procedimentos para conseguir aumentar ou preservar a beleza corpórea. Muitas, mesmo tendo de utilizar de procedimentos que exigem alto custo emocional, físico ou financeiro, recorrem a esses procedimentos em razão das recompensas emocionais, sociais e materiais que a condição de ser belo proporciona no mundo contemporâneo.

No conto, percebemos que o patinho passou a acreditar, devido aos reforços que recebeu em seu meio familiar, que por ter sua aparência diferente dos outros, seria então muito feio, e que por esse motivo os demais o maltratariam, acreditando também que a sua fisionomia assustava. $O$ filhote, ao entender a violência como sua própria culpa, acaba criando uma falsa imagem de si mesmo. O que chama a atenção no conto é que quando o patinho larga a família e vai buscar novos horizontes, voa por cima da cerca. Compreendemos esse movimento como uma simbologia da busca da sua própria identidade, a busca do próprio espaço. Todavia, nos humanos isso só poderá ser feito a partir da fase da adolescência, ou a partir da entrada do mundo adulto, momento que o jovem terá condições de se manter sozinho.

$O$ conto traz também referências que permitem perceber identificar o desenvolvimento físico do patinho, pois aprende a voar, aprende a nadar, ações que estão associadas a uma perspectiva biológica. Isso nos parece importante, na medida em que associamos às fases do desenvolvimento da criança que, ao atingir a adolescência, passa a discordar dos ditames familiares, indo em busca de seu espaço, de seus objetivos. O conto se mostra bastante contemporâneo e é pertinente que possamos considerar que os conflitos que são tratados nessa história estão muito ligados à realidade de vida dos humanos.

Conforme dizem, Bellak e Hurvich (1992), para alguns sujeitos se torna muito mais fácil se expressar por meio de figuras animais ao invés de figuras humanas. Talvez por esse motivo Andersen optou em criar o personagem $O$ Patinho Feio, podendo, assim, expressar todo o seu sofrimento e conflitos que vivenciara em sua infância. Schneider e Torossian (2009), comentam que a obra é conhecida por ser o retrato da vida do autor e seu difícil percurso. Notamos tamanha coincidência em um animalzinho vivenciar situações conflitantes e, de certa forma, tão semelhantes a um mundo tão conhecido por humanos. Isso 
possibilita que as pessoas que leem ou ouvem essa história possam se identificar com essa problemática e encontrar significado para algumas conflitivas, tendo esperança de elaboração no futuro de suas dores. É possível que possam, assim, repensar sua condição de vida, fator que assinala a atualidade do conto ainda nos dias atuais.

Nesse sentido, Corso e Corso (2006) preconizam que as narrativas infantis são como caixas de ferramentas que possibilitam as operações necessárias. Contudo, essas só serão possíveis com a chave de fenda, a broca, ou o alicate adequado. Além do mais, com o uso dessas ferramentas, podemos criar, construir e transformar objetos e lugares.

Mais ao final do conto, percebemos que, com a permanência do inverno, o patinho acaba preso dentre o gelo. Assim, o filhote conta com a ajuda de pessoas que o salvam da morte, no caso, um camponês. Com isso, há um novo investimento na potencialidade de vida desse filhote. Porém, devido aos desafios cruéis que enfrentou em toda sua trajetória familiar e social, não acredita mais nos contatos que lhe aparecem, acaba ficando defensivo, pensando que todos que se aproximam vão querer lhe fazer mal, construindo uma visão deturpada de si mesmo.

Esse episódio da narrativa pode nos levar a pensar que o pavor por não se reconhecer como um ser de valor, com a autoestima rebaixada, pode ter sido o motivo para não se aproximar dos cisnes na primeira vez que os viu. A dor já conhecida de ser maltratado e desprezado o impede de se aproximar, deixa-o paralisado. Possivelmente, existiria um sentimento de vergonha pelo que pensava de si, causando também esse bloqueio. Nesse ponto, o conto também parece traduzir o que se passa no psiquismo infantil. Sabemos que crianças que foram maltratadas, humilhadas podem criar uma imagem negativa de si mesmas, o que interfere em sua capacidade de resiliência de enfrentar as mudanças.

Finalmente, o patinho feio fugirá da casa do camponês, encontrando novamente as aves maravilhosas. Decide, dessa vez, ir ao encontro delas, mesmo acreditando que possa ser maltratado. "Que viu ele na água cristalina? Era a sua própria imagem, refletida ali. Mas não era de um pato, de um pardo e feio pato. Era um cisne que ele via no espelho da agua" (p. 250). Obviamente, alguma mudança interna ocorreu com o patinho. Simbolicamente, poder-se-ia deduzir que esse amadureceu suficientemente para ir ao encontro de sua família de origem, enfrentando os enigmas do mundo adulto. Ao se observar no lago, reconhece sua nova imagem, percebendo-se diferente e, provavelmente, isso lhe dá coragem para fazer novas inserções no ambiente. Assim, feliz por ter reconhecido a sua beleza, nunca antes percebida, é rodeado pela família dos cisnes que lhe catavam a nuca com o bico.

Ressaltamos que esse mesmo gesto de investimento afetivo e libidinal foi 
utilizado pelo autor quando descreveu a mãe pata reconhecendo o filho, ainda no início do conto. Depreendemos, pois, que a partir do momento em que é aceito e acolhido pelos cisnes, o patinho é reconhecido pelos seus semelhantes, por sua família de origem. No mundo humano, sabemos o quanto importante é, para uma criança, ainda que já pertencente a um lar, conhecer sua história original, indo assim em busca de complementar sua história de vida. É isso que parece ter acontecido com o patinho, quando encontra os seus.

Esse final feliz do encontro do patinho feio (cisne) com seus pares parece simbolicamente revelar um sonho universal das crianças, adotadas ou não, de serem reconhecidas e amadas. Pertencer a um grupo, ser reconhecido pelos semelhantes é uma necessidade compartilhada universalmente. Por esse motivo, novamente, percebemos que Andersen, por meio do conto $O$ Patinho Feio delineia assuntos pertinentes ao universo contemporâneo, trazendo à tona questões sociais que falam sobre dilemas cotidianos enfrentados por crianças, adultos e famílias.

Depreende-se que as narrativas infantis, sejam elas com a presença de fadas ou com a presença do maravilhoso, são importantes para o desenvolvimento infantil. Entre os inúmeros contos existentes, percebemos no conto analisado que a condição do patinho feio que se transforma em cisne pode possibilitar ao psiquismo infantil a elaboração de conflitos urgentes para determinados momentos de uma vida, permitindo que o indivíduo dê destino, de forma lúdica, à angústia do crescimento, dos conflitos com a autoimagem, representando um caminho alternativo para elaboração dessas angústias do desenvolvimento.

\section{Considerações finais}

$\mathrm{O}$ ato de contar histórias é conhecido e transmitido ao longo das gerações. Conforme Rosa (2015), os contos exploram as dimensões mais profundas de dramas humanos universais, configurando-se, portanto, em narrativas de alto valor simbólico.

No conto $O$ Patinho Feio, há de se ressaltar os ganhos do personagem, relacionando-os também ao cuidado materno. A pata, sua mãe, soube fortalecer sua estrutura psíquica, investiu em suas necessidades emocionais e físicas, com isso fortalecendo-o, dando condições para que esse pudesse voar, nadar e buscar novos horizontes, sem desmoronar. Aliás, este cuidado inicial de sua mãe, por vezes passa despercebido nos resumos consideravelmente sintetizados que foram editados desse conto.

Retomamos ainda Bettelheim (1903) que pontua a razão de as histórias terem tanto êxito no enriquecimento da vida interior infantil, já que em um sentido bem mais profundo do que outros tipos de leitura, começam onde a criança se encontra em seu real estado psicológico emocional. As histórias falam de pres- 
sões internas graves, de maneira que a criança, inconscientemente, compreende, oferecendo exemplos tanto de soluções temporárias quanto permanentes para dificuldades urgentes.

Complementarmente, o conto possibilitaria muitos vieses de análise, mas enveredamos por algumas compreensões que despertaram maior atenção. Machado (2004, p. 23) diz que "[...] cada pessoa mostra que ouviu 'um' conto, o seu. Algumas coisas chamaram sua atenção, outras não". Assim, essa análise tem o olhar intermediado pela formação dos autores nas áreas de psicologia e letras. Outros olhares, certamente são possíveis.

Destacamos, por fim, que a análise dos contos pode ser um importante instrumento para acessar e falar de conflitos dolorosos para o indivíduo, uma vez que possibilita tocar o mundo interno, permitindo a elaboração de alguns conflitos. Isso explicaria a permanência dos contos antigos, que vão sendo atualizados e continuam dando sentido para e expressão dos conflitos humanos. Os contos são ainda uma forma indireta de significar as profundezas de um aparelho psíquico ágil em constante metamorfose.

\section{Children narratives as a} possibility of symbolizing childhood conflicts: an analysis of The Ugly Duckling fairy tale

This study aims to identify and to describe the importance of storytelling for children's psychological and emotional development. Thus, from the original version of Andersen's Ugly Duckling fairy tale, it was performed a reflection on the possibility of narratives to become important tools to bring out emergent conflicts, especially during childhood, therefore contributing to the identification and elaboration of ludic contents that might cause anguish to the individual, allowing them to reorganize their psychological and emotional state.

Keywords: Children narratives. Childhood. Symbolizing.

\section{Notas}

1 Este conto, escrito pelo dinamarquês Hans Christian Andersen (1843), retrata a história de um filhote de cisne que foi chocado no ninho de uma pata e, consequentemente, sendo diferente dos outros filhotes, é perseguido, ofendido e maltratado.

2 Como o conto é bastante extenso (12 páginas), optamos por resumir a história. No entanto, quando mantivermos as palavras originais do conto, empregaremos itálico, para sinalizar ao leitor. Informamos que, embora o conto tenha sido publicado pela primeira vez em 1843, trabalhamos com a edição de 1893. 


\section{Referências}

ANDERSEN, Hans Christian. Contos de Andersen. São Paulo: Martins Fontes, 1993.

BENVENISTE, É. Problemas de Linguística Geral I. Campinas, SP: Pontes, 1995.

BELLAK, Leopold; HURVICH, Marvin S. C. A. T. H: teste de apercepção infantil: figuras humanas. Campinas: Psy, 1992.

BETTELHEIM, Bruno. A psicanálise dos contos de fadas. Rio de Janeiro: Paz e Terra, 1903.

COELHO, Betty. Contar histórias: uma arte sem idade. São Paulo: Ática, 1997.

COELHO, Nelly Novaes. $O$ conto de fadas. São Paulo: Ática, 1987.

CORSO, Diana Lichtenstein; CORSO, Mário. A psicanálise na Terra do Nunca: ensaios sobre a fantasia. Porto Alegre: Penso, 2011.

Fadas no divã: psicanálise nas histórias infantis. Porto Alegre: Artmed, 2006.

DORFMAN, Ariel; MATTELART, Armand. Para ler o Pato Donald: comunicação de massa e colonialismo. 3. ed. Rio de Janeiro: Paz e Terra, 1982.

MACHADO, Regina. Acordais: fundamentos teórico-poéticos da arte de contar histórias. São Paulo: DCL, 2004.

ROSA, Luciana Lhullier. No coração da floresta. Passo Fundo: Edição do Autor, 2015.

SANTOS, Dóris M. Wittmann dos; SANTOS FILHO, Francisco Carlos dos; AQUINO, Ivania Campigotto (Coord.). Te conto um conto: um enlace entre psicanálise e literatura infantil. 2. ed. Passo Fundo: UPF Editora, 2009.

SCHNEIDER, Finger. E. R; TOROSSIAN, Djambolakdijan. S. Contos de fadas: de sua origem a clínica contemporânea. Psicologia em Revista, Belo Horizonte, v. 15, n. 2, 2009. Disponível em: <http://pepsic. bvsalud.org/scielo.php?script=sci_arttex-
t\&pid=S167711682009000200009 $>$. Acesso em: 17 jun. 2017.

SILVA, Ana Beatriz Barbosa. Mentes perigosas nas escolas: bullying. Rio de Janeiro: Fontanar, 2010.

TEIXEIRA, Alves. S. Produção e consumo social da beleza. Horizontes Antropológicos, Porto Alegre, v. 7, n. 16, 2001. Disponível em: <http://www.scielo.br/scielo.php?pi$\mathrm{d}=\mathrm{S} 010471832001000200011 \&$ script $=\mathrm{s}-$ ci_arttext>. Acesso em: 17 jun. 2017. 